Diabetologia 11, 555-559(1975)

(C) by Springer-Verlag 1975

\title{
The Contribution of Endogenous Insulin Secretion to the Ketogenic Response to Glucagon in Man*
}

\author{
D. S. Schade and R. P. Eaton \\ Dept. of Medicine, Univ, of New Mexico School of Medicine, Albuquerque, New Mexico, USA
}

Received: May 26, 1975, and in revised form: September 3, 1975

\begin{abstract}
Summary. The magnitude and direction of the lipolytic and ketogenic responses following exogenous glucagon administration is controversial and consideration of the possible role of endogenous insulin secretion upon these events has not been clarified. The present study examines the role of endogenous insulin secretion in modulating the net lipolytic and ketogenic activity of glucagon. Three groups characterized by different levels of endogenous insulin secretory capacity were studied. In all three groups, the responses in plasma insulin, betahydroxybutyrate, and free fatty acids were observed following bolus administration of $1.0 \mu \mathrm{g} / \mathrm{kg}$ glucagon. In the obese subjects with increased endogenous insulin secretion, glucagon administration resulted in a decline below basal
\end{abstract}

levels of both free fatty acid and betahydroxybutyrate. In the diabetic subjects with no demonstrable endogenous insulin secretion, glucagon administration was followed by a rise in plasma free fatty acids and an exaggerated rise in plasma betahydroxybutyrate. The normal control group exhibited a response in betahydroxybutyrate midway between the obese and diabetic groups. These observations support the thesis that the magnitude of endogenous insulin secretion modulates the lipolytic and ketogenic actions of glucagon in man.

Key words: Insulin, glucagon, ketogenic, lipolytic, betahydroxybutyrate, ketone, obese, diabetic, free fatty acid, diabetic ketosis.
A contribution by glucagon to the hyperglycemia of diabetes mellitus has recently been reported [1]. Moreover, recent reports [2-4] support a role for this hormone in the associated problem of ketosis and ketoacidosis. Since the plasma concentration of ketone bodies is a reflection of both hepatic production and peripheral utilization, glucagon may exert an effect at either, or both, of these sites. In vivo studies have demonstrated that glucagon augments hepatic ketogenesis in insulin deficient man, but whether this augmentation occurs directly at the hepatocyte or indirectly by increasing free fatty acid (FFA) substrate availability from the adipocyte is unresolved. This augmentation has not been demonstrated in nondiabetic man, where an apparent decline in hepatic ketogenesis and peripheral plasma ketone body concentration has been observed $[5,6]$. An effect of glucagon on peripheral ketone body disposal has not been reported.

The hepatic production of ketone bodies is determined, in part, by both the availability of free fatty acid substrate [7] and the intrinsic ketogenic "set" of the liver [8]. Since insulin suppresses both of these determinants and may enhance peripheral ketone body utilization [9], the endogenous secretion of insulin in response to glucagon stimulation could modu-

* This work was done while D. S. Schade was a Research Associate of the American Diabetes Association late the net ketogenic response to glucagon in man. Thus, the presence of endogenous insulin secretion could explain the absent ketogenic response to glucagon in non-diabetic man as compared to insulin deficient, diabetic man. In order to evaluate this possibility, we have examined the ketogenic response to a pharmacological dosage of glucagon in three groups of humans characterized by different levels of endogenous insulin secretion: 1 . An obese non-diabetic group with elevated endogenous insulin secretion; 2 . A normal weight non-diabetic groups with normal endogenous insulin secretion; and 3. A normal weight insulin deficient diabetic group with no endogenous insulin secretion. Utilizing this approach, we have assessed the importance of the antiketogenic actions of insulin upon glucagon stimulated ketosis.

\section{Material and Methods}

The characteristics of the three groups of subjects studied are given in Table 1 . In each subject, the presence or absence of diabetes mellitus and the magnitude of endogenous insulin secretion was established by the change in plasma glucose and insulin concentration after a standard $100 \mathrm{~g}$ oral glucose tolerance test. Diabetes was defined by utilizing the U.G.D.P. criteria [10]. Group I consisted of previously reported [11] non-diabetic obese patients with ele- 
Table 1. Characteristics of the groups studied

\begin{tabular}{|c|c|c|c|}
\hline Parameter & $\begin{array}{l}\text { Group I } \\
\text { (Obese) }\end{array}$ & $\begin{array}{l}\text { Group II } \\
\text { (Normal) }\end{array}$ & $\begin{array}{l}\text { Group III } \\
\text { (Diabetic) }\end{array}$ \\
\hline No. of Subjects & 5 & 5 & 5 \\
\hline $\begin{array}{l}\text { Weight } \\
\text { (\% Ideal Weight) }\end{array}$ & $180 \pm 20 \%$ & $100 \pm 10 \%$ & $100 \pm 10 \%$ \\
\hline Age Range (Years) & $24-32$ & $22-25$ & $20-25$ \\
\hline Medication & None & None & $\begin{array}{l}\text { NPH Insulin } \\
24-40 \text { Units daily }\end{array}$ \\
\hline $\operatorname{Sex} \mathbf{M} / \mathbf{F}$ & $0 / 5$ & $2 / 3$ & $3 / 2$ \\
\hline \multicolumn{4}{|l|}{$\begin{array}{l}\text { Oral GTT } \\
\text { Sum of } 0,1,2,3 \mathrm{hrs}\end{array}$} \\
\hline $\begin{array}{l}\text { Glucose Sum: } \\
\text { Insulin Sum: }\end{array}$ & $\begin{array}{l}362 \pm 39 \mathrm{mg} / \mathrm{dl} \\
349 \pm 42 \mu \mathrm{U} / \mathrm{ml}\end{array}$ & $\begin{array}{l}355 \pm 32 \mathrm{mg} / \mathrm{dl} \\
123 \pm 21 \mu \mathrm{U} / \mathrm{ml}\end{array}$ & a \\
\hline
\end{tabular}

a Oral glucose tolerance tests were not performed on the insulin requiring diabetic subjects. Instead, an acute ten gram glucose bolus was administered intravenously and serial blood samples for insulin and glucose were drawn during the subsequent twenty minutes. At five minutes post-injection, maximal increase of glucose above basal values was obtained $(71 \pm 8 \mathrm{mg} / \mathrm{dl})$ and no insulin secretion could be demonstrated $(0 \pm 3 \mu \mathrm{U} / \mathrm{mI})$

vated endogenous insulin secretion; Group II consisted of non-diabetic normal weight subjects with normal endogenous insulin secretion, and Group III were normal weight insulin dependent diabetics with no endogenous, glucose stimulated insulin secretion, measured following removal of endogenous insulin antibody with polyethylene glycol [12].

All tests were conducted at 7:00 a.m. after a 12 hours overnight fast. Each subject assumed the supine position for $20 \mathrm{~min}$ prior to blood sampling and maintained this position throughout the test period. Glucagon was obtained from Eli Lilly \& Co. (Indianapolis, Indiana) in $1 \mathrm{mg}$ vials and diluted with $250 \mathrm{ml}$ of isotonic saline to obtain a final concentration of 4 $\mu \mathrm{g} / \mathrm{ml}$. Minimal insulin $(<20 \mu \mathrm{U} / \mathrm{ml})$ by radioimmunoassay was present in this final dilution. On separate days, subjects were tested with either an intravenous control saline injection or an intravenous glucagon injection at a pharmacological dosage of 1.0 $\mu \mathrm{g} / \mathrm{kg}$. Thus, the glucagon dosage was administered on the basis of body weight, such that obese subjects received a proportionally greater amount of hormone than did normal weight subjects. The solutions were drawn into a plastic syringe and injected over a ten second period. To avoid loss of glucagon by nonspecific adherence, the syringe was rinsed and reinjected three times with venous blood obtained retrograde from the patient's vein immediately after hormone injection.
An 18 gauge needle was placed in the antecubital vein of the contralateral arm and patency was maintained by a slow drip of isotonic saline. All blood samples were withdrawn from this vein after discarding the initial $3 \mathrm{ml}$ of blood. Samples were withdrawn at the following times: 0 (just prior to injection), $+2,+5,+10,+15$, and +20 min post-injection of glucagon, and assayed for insulin, betahydroxybutyrate $^{1}(\mathrm{BOH})$ and free fatty acids (FFA), as previously described [13].

Prior to insulin assay, plasma from the diabetic patients was treated with $25 \%$ polyethylene glycol to remove endogenous antibody [12]. As reported in detail by Nakagawa et al. [12], and confirmed in our laboratory, this allows the determination of free insulin in the sera of insulin-treated diabetics in which varying amounts of anti-insulin antibody may be present. Over a range of insulin concentration from $10-1000 \mu \mathrm{U} / \mathrm{ml}$, a recovery of $76 \pm 6 \%$ was observed. The effect of glucagon upon the concentration of plasma metabolites was calculated as the change post glucagon compared to the baseline value obtained immediately prior to the experimental injection. Statistical evaluation was performed as described by Bahn [14], and the significance of the difference between populations means was calculated by use of Student's " $t$ " test for nonpaired samples [14].

\footnotetext{
1 3-hydroxybutyrate
} 


\section{Results}

\section{Plasma Insulin Secretion $\mu \mathrm{U} / \mathrm{ml}$ \\ (Fig. 1 - Upper Third) Mean \pm SEM}

As depicted in the upper third of Fig. 1, the magnitude of the change in plasma insulin secretion following glucagon stimulation was greatest in the obese group, intermediate in the normal group, and absent in the diabetic group. This order of insulin response was similar to that observed following the glucose tolerance test (Table 1). Compared to the integrated insulin response in the normal group (273 $\pm 53 \mu \mathrm{U} / \mathrm{ml} \cdot \mathrm{min})$, the obese subjects hypersecreted insulin after exogenous glucagon administration $(1008 \pm 277 \mu \mathrm{U} / \mathrm{ml} \cdot \min ) p<0.01$. In contrast to both

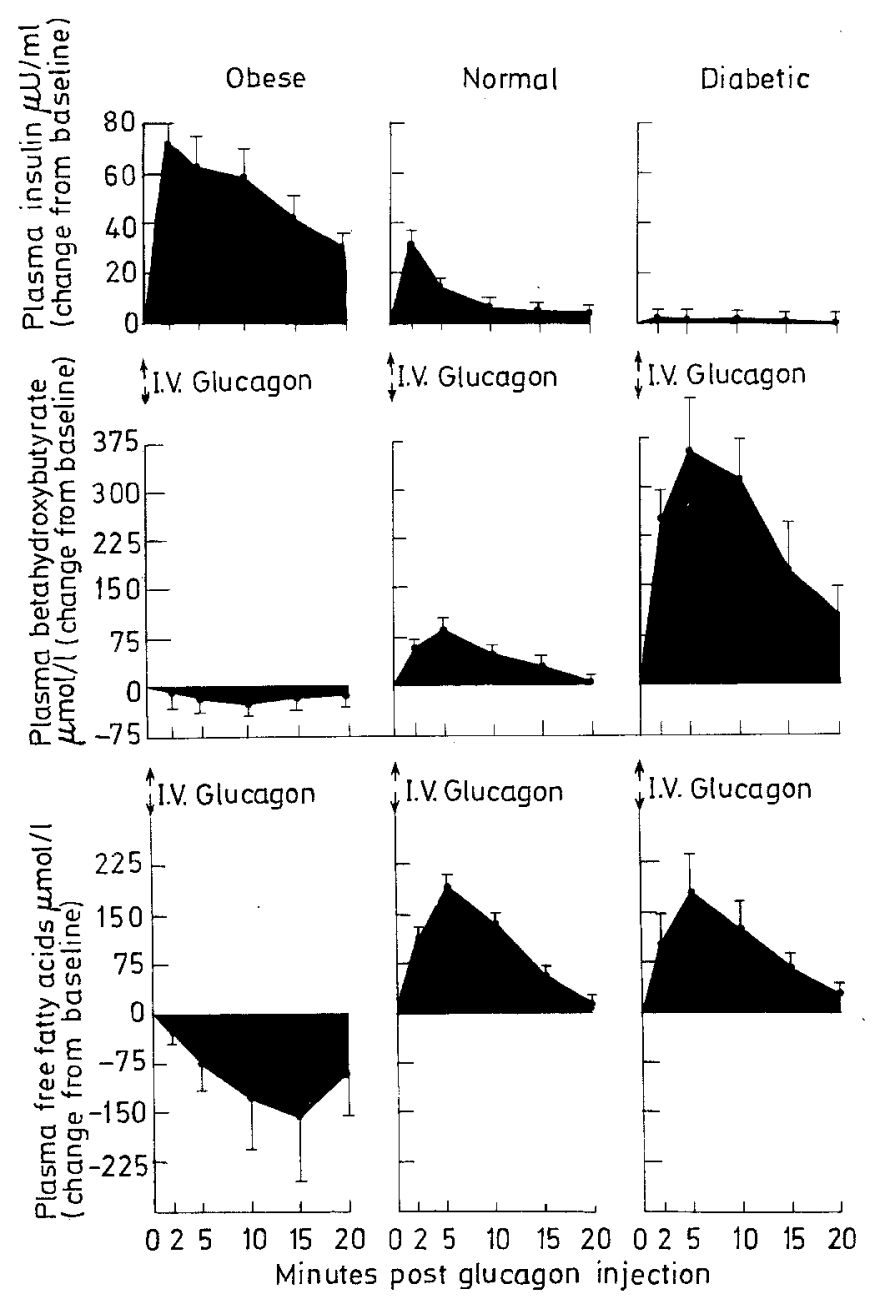

Fig. 1. Ketogenic response to glucagon in relation to endogenous insulin secretion. Changes from basal level in the plasma concentration of insulin, betahydroxybutyrate, and free fatty acid following exogenous bolus glucagon administration $(1.0 \mu \mathrm{g} / \mathrm{kg})$. The response in the obese, normal, and diabetic populations are depicted in the first, second, and third columns respectively the obese group and the normal group, no statistically significant rise in plasma insulin could be detected in any diabetic subject $(11 \pm 11 \mu \mathrm{U} / \mathrm{ml} \cdot \mathrm{min})$. Therefore, as expected from their clinical status, the endogenous insulin secretion after both glucose and glucagon stimuli was greatest for Group I, intermediate in Group II, and absent in Group III.

\section{Plasma Betahydroxybutyrate Response $\mu \mathrm{mol} / \mathrm{L}$ (Fig. 1 - Middle Third)}

After glucagon stimulation, all subjects demonstrated a change in plasma $\mathrm{BOH}$ concentration. However, although all subjects received the same stimulatory dose of glucagon on a weight basis $(1.0 \mu \mathrm{g} / \mathrm{kg})$, the response of $\mathrm{BOH}$ differed significantly in each group $(p<0.01)$ and was inversely related to the magnitude of the change in plasma insulin concentration shown in the top panel of Fig. 1. The change in plasma $\mathrm{BOH}$ in the obese group with maximal endogenous insulin secretion was actually a reduction in ketone concentration, contrasting with the normal and insulin deficient group both of which demonstrated a rise in ketone concentration. The integrated area of the $\mathrm{BOH}$ response in the obese subjects $(-360 \pm 370 \mu \mathrm{mol} / \mathrm{L} \cdot \mathrm{min})$ was significantly less than that observed in the normal subjects $(+738 \pm 108$ $\mu \mathrm{mol} / \mathrm{L} \cdot \min ) p<0.01$. In addition, the integrated area of the normal group $(+738 \pm 108 \mu \mathrm{mol} / \mathrm{L}: \min )$ was significantly less than that of the diabetic population $(4349 \pm 1103 \mu \mathrm{M} / \mathrm{L} \cdot \min ) p<0.01$. These data suggest that endogenous insulin secretion modulates the ketogenic response to exogenous glucagon injection and, when excessive, can suppress plasma ketone bodies below basal values as observed in the obese subjects.

\section{Plasma Free Fatty Acid $\mu M / L$ - Fig. 1 - Lower Third)}

Although insulin is known to inhibit peripheral lipolysis, resulting in a reduction in plasma FFA concentration, the change in plasma FFA concentration following glucagon injection was not statistically different between the normal and insulin deficient groups $(p<0.05)$. Thus, the mean integrated area defining the rise in plasma FFA in the normal group $(2034 \pm 145 \mu \mathrm{mol} / \mathrm{L} \cdot \mathrm{min})$ did not differ statistically from the mean integrated area of the diabetic group $(1998 \pm 638 \mu \mathrm{mol} / \mathrm{L} \cdot \mathrm{min})$. These responses contrasted with the unexpected reduction in FFA in response to glucagon in the obese group $(-1438 \pm$ $1239 \mu \mathrm{mol} / \mathrm{L} \cdot \mathrm{min}$ ); this was significantly lower than that observed in the normal and diabetic groups $p<$ 0.01 . 


\section{Discussion}

Our results suggest that pharmacological dosages of glucagon elevate plasma ketones in non-obese man and that this elevation is inversely related to the magnitude of endogenous insulin secretion. The greatest increase in plasma betahydroxybutyrate concentration following glucagon administration was observed in the insulin deficient diabetic group, with no demonstrable endogenous insulin secretion. In contrast, an actual decrease in plasma $\mathrm{BOH}$ was observed following glucagon injection in the hyperinsulinemic obese group suggesting that the antiketotic action of the hypersecreted endogenous insulin obscured the ketotic effects of glucagon. There are two possible sites at which insulin might negate the ketogenic action of glucagon: 1. at the adipocyte and/or 2. at the hepatocyte. At the adipocyte glucagon has been demonstrated to be lipolytic both in vitro [15] and in vivo [16]; this lipolytic action is antagonized by insulin [17]. Whether the lipolytic action of glucagon is a direct action of this hormone on the adipocyte or is secondary to a glucagon induced release of epinephrine [18] is not resolved by our study. In any event, since hepatic ketogenesis is proportional to the plasma concentration of free fatty acid substrate [7], glucagon's lipolytic action would be expected to result in enhanced hepatic ketogenesis. In the obese group, the administration of glucagon resulted in hypersecretion of insulin and a net antilipolytic response, suggesting that insulin antagonized the lipolytic effects of glucagon at the adipocyte with a net reduction in ketogenesis. In contrast to the insulin excess obese group, a lipolytic response was observed in both our normal control group and our insulin deficient group and undoubtedly contributed to the increase in plasma ketone body concentration. However, hormonal regulation exclusively at the adipocyte cannot explain the greater rise in plasma ketones in the diabetic patients compared with the normal subjects. In these two groups, an indistinguishable rise in FFA was associated with a greatly different rise in $\mathrm{BOH}$, suggesting hormonal regulation at additional sites.

At the hepatocyte, betahydroxybutyrate is produced in the mitochondria by oxidation of these FFA [19]. In the fasting state, the majority of this FFA is derived from lipolysis of adipose tissue triglyceride [20]. After mitochondrial production, $\mathrm{BOH}$ is released into the circulation via the hepatic vein and utilized for oxidation by peripheral tissues [21]. The rate of hepatic ketogenesis is influenced by multiple factors, including availability of FFA substrate, concentration of hepatocyte gluconeogenic substrates, hepatic enzymatic activity, and hormonal concentra- tions, particularly insulin and glucagon [8]. In the isolated perfused rat liver, Heimberg et al. [7] demonstrated that glucagon stimulated ketogenesis at all concentrations of free fatty acid up to $1.5 \mathrm{mM}$. Moreover, in a similar system, insulin has been shown to inhibit hepatic ketogenesis [22]. Parilla et al. [23], have simultaneously examined the effects of both hormones in the perfused rat liver and have suggested that the molar ratio of glucagon to insulin may determine the net metabolic "set" of the liver. Our results are consistent with the modulation of hepatic ketogenesis by glucagon and insulin at the hepatocyte. The greater rise in $\mathrm{BOH}$ concentration in the insulin deficient diabetics than in the normal subjects, in spite of a similar rise in FFA substrate, suggests that the ketogenic action of glucagon is more pronounced when unopposed by the antiketogenic effects of endogenous insulin secretion. It should be noted that the other major plasma ketone body, acetoacetate, has not been measured in our studies. It is possible that a shift in the ratio of these ketone bodies could influence the interpretation of our data.

Since the plasma metabolite concentration is determined by the balance between production and utilization, any alteration in peripheral utilization of betahydroxybutyrate during this study might be reflected in changes in the plasma concentration of this substrate. Insulin has been reported to enhance peripheral utilization of ketone bodies when administered to both the diabetic rat [24] and the diabetic dog [9]. No direct studies are available on the effects of glucagon on ketone body utilization. However, during fasting, a state characterized by increased glucagon secretion and decreased insulin secretion, the peripheral clearance of both acetoacetate [25] and betahydroxybutyrate [26] is significantly prolonged. In our study, the elevated plasma insulin levels of the obese population could effect a net reduction in plasma ketones by augmenting peripheral ketone clearance as well as by inhibiting lipolysis and altering hepatocyte conversion to ketones. Similarly, the reduced level of insulin in the diabetic population could result in reduced ketone clearance, contributing to the large increase in plasma ketones following glucagon administration. Thus, the endogenous secretion of insulin may be implicated in modulating the net ketone responses to exogenous glucagon in man whether it be at the adipocyte, hepatocyte, or peripheral tissues.

In summary, our studies suggest that glucagon is ketogenic in man and may be particularly important in the pathogenesis of diabetic ketosis in which both increased endogenous glucagon and decreased endogenous insulin is characteristic [1]. Based on our observations that the magnitude of the ketogenic response 
to glucagon is inversely related to the endogenous insulin secretory capacity, this hormonal derangement in insulin deficient diabetics would result in greatly augmented plasma ketone body concentration. Thus, rational therapy for ketoacidosis might include both suppression of endogenous glucagon and supplementation of endogenous insulin secretion.

Acknowledgements. We are grateful to I. Pommer and R. Temple for skillful technical assistance. This investigation was supported by grants from the KROC Foundation and The American Diabetes Association.

\section{References}

1. Unger, R. H., Orci, L.: The essential role of glucagon in the pathogenesis of diabetes mellitus. Lancet 1975 I, 14-16

2. Gerich, J. E., Tsalikian, E., Lorenzi, M., Karam, J. H., Bier, D. M.: Plasma glucagon and alanine responses to acute insulin deficiency in man. J. clin. Endocr. 40, 526-529 (1975)

3. Alberti, K. G. M.M., Christensen, N.J., Iversen, J., Ørskov, H.: The role of glucagon and other hormones in development of diabetic ketoacidosis. Lancet 1975, I 1307-1311

4. Gerich, J. E., Lorenzi, M., Bier, D. M., Schneider, V., Tsalikian, E., Karam, J. H., Forsham, P. H.: Prevention of human diabetic ketoacidosis by somatostatin. New Engl. J. Med. 292, 985-989 (1975)

5. Liljenquist, J. E., Bomboy, J. D., Lewis, S. B., Sinclair Smith, B. C., Felts, P. W., Lacy, W. W., Crofford, O. B., Liddle, B. W.: Effects of glucagon on lipolysis and ketogenesis in normal and diabetic men. J. clin. Invest. 53, 190-197 (1974)

6. Salter, J. M., Ezrin, C., Laidlaw, J. C., Cornall, A. G.: Metabolic effects of glucagon in human subjects. Metabolism 9, 753-768 (1960)

7. Heimberg, M., Weinstein, I., Kohout, M.: The effects of glucagon, dibutyryl cyclic AMP, and the concentrations of free fatty acids on hepatic lipid metabolism. J. Biochem. (Tokyo) 244, 5131-5139 (1969)

8. McGarry, J. D., Foster, D. W.: Regulation of ketogenesis and clinical aspects of the ketotic state. Metabolism 21, 471-489 (1972)

9. Balasse, E. O., Havel, R. G.: Evidence of an effect of insulin on the peripheral utilization of ketone bodies in dogs. J. clin. Invest. 50, 801-817 (1971)

10. Klimt, C. R., Knatterud, G. L., Meinert, C. L., Prout, T. E.: A study of the effects of hypoglycemic agents on vascular complications in patients with adult-onset diabetes. Diabetes 19 , 747-783 (1970)

11. Schade, D. S., Eaton, R. P.: Altered tissue response to glucagon in obesity. J. clin. Endocr. 40, 732-735 (1975)
12. Nakagawa, S., Nakayama, H., Sasaki, T., Yoshino, K., Yu, Y. Y., Shinozaki, K., Aoki, S., Mashimo, K.: A simple method for the determination of serum free insulin levels in insulin treated patients. Diabetes 22, 590-600 (1973)

13. Schade, D. S., Eaton, R. P.: Modulation of free fatty acid metabolism in man I. Diabetes 24, 502-509 (1975)

14. Bahn, A. K.: Basic medical statistics, 1st Ed., p. 134. New York: Grune and Stratton 1972

15. Lewis, G. P., Mathew, J.: The mobilization of free fatty acids from rabbit adipose tissue. Brit. J. Pharmacol. 34, 564-578 (1968)

16. Lefebvre, P.: The physiological effect of glucagon on fat mobilization. Diabetologia 2, 130-134 (1966)

17. Mahler, R., Stafford, W. S., Tarrant, M. E., Ashmore, J.: The effect of insulin on lipolysis. Diabetes 13, 297-302 (1964)

18. Sarcione, E. J., Back, N., Sokal, J. E., Mehlman, B., Knoblock, E.: Elevation of plasma epinephrine levels produced by glucagon in vivo. Endocrinology 72, 523-526 (1963)

19. Basso, L. V., Havel, R. J.: Hepatic metabolism of free fatty acids in normal and diabetic dogs. J. clin. Invest. 49, 537-547 (1970)

20. Barter, P. J., Nestel, P. J.: Plasma free fatty acid transport during prolonged glucose consumption and its relationship to plasma triglyceride fatty acids in man. J. Lipid Res. 13, 483-490 (1972)

21. Garber, A. J., Menzel, P. H., Boden, G., Owen, O. E.: Hepatic ketogenesis and gluconeogenesis in humans. J. clin. Invest. 54, 981-989 (1974)

22. Heimberg, M., Van Harken, D. R., Weinstein, I., Kohout, M.: Regulatory factors in ketogenesis and in the metabolism of triglycerides by liver. Advanc. Exp. Biol. Med. 4, 185-200 (1969)

23. Parilla, R., Goodman, M. N., Toews, C. J.: Effect of glucagon: Insulin ratios on hepatic metabolism. Diabetes 23, 725-731 (1974)

24. Beatty, C. H., Peterson, R. D., Bocek, R. M., West, E.: Acetoacetate and glucose uptake by diaphragm and skeletal muscle from control and diabetic rats. J. biol. chem. 234, 11-15 (1959)

25. Owen, O. E., Reichard, G. A., Jr., Markusit., Boden, G., Mozzoli, M. A., Shuman, C. R.: Rapid intravenous sodium acetoacetate infusions in man. J. clin. Invest. 52, 2606-2616 (1973)

26. Grey, N. M., Karl, I., Kipnis, D. M.: Physiologic mechanisms in the development of starvation ketosis in man. Diabetes 24, $10-16(1975)$

R. Philip Eaton, M. D.

Professor of Medicine

Division of Endocrinology

Department of Medicine

University of New Mexico School of Medicine

Albuquerque, New Mexico 87131

USA 